\title{
PHARMACOKINETICS OF OXYTETRACYCLINE IN LOGGERHEAD SEA TURTLES (CARETTA CARETTA) AFTER SINGLE INTRAVENOUS AND INTRAMUSCULAR INJECTIONS
}

\author{
Craig A. Harms, D.V.M., Ph.D., Dipl. A.C.Z.M., Mark G. Papich, D.V.M., M.S., Dipl. A.C.V.C.P., \\ M. Andrew Stamper, D.V.M., Dipl. A.C.Z.M., Patricia M. Ross, D.V.M., Mauricio X. Rodriguez, \\ and Aleta A. Hohn, Ph.D.
}

\begin{abstract}
The pharmacokinetics of oxytetracycline in 2-yr-old loggerhead sea turtles (Caretta caretta) after single i.v. and i.m. injections were studied for biologic marking and therapeutic applications. Twenty juvenile turtles were divided into two treatment groups. Ten animals received $25 \mathrm{mg} / \mathrm{kg}$ of oxytetracycline i.v. and 10 received the same dosage i.m. Plasma oxytetracycline concentrations were analyzed by reverse-phase high-performance liquid chromatography. Data from the i.v. route best fit a three-compartment model, whereas noncompartmental analysis was used to compare data from both the i.v. and i.m routes. For the i.v. route, means for maximum plasma concentration, terminal phase half-life, systemic clearance, and apparent volume of distribution at steady state were $6.6 \mu \mathrm{g} / \mathrm{ml}, 66.1 \mathrm{hr}, 290.7$ $\mathrm{ml} / \mathrm{hr} / \mathrm{kg}$, and $18.4 \mathrm{~L}$, respectively. For the i.m. route, means for systemic availability, maximum plasma concentration, and elimination half-life were $91.8 \%, 1.6 \mu \mathrm{g} / \mathrm{ml}$, and $61.9 \mathrm{hr}$, respectively. The remarkably high apparent volume of distribution may possibly be associated with a deep compartment of drug disposition such as bone deposition associated with the large skeletal mass of turtles and the fact that these were well-nourished, growing juveniles. Although maximum plasma concentration by i.m. administration was lower than for the i.v. route, the long elimination time indicates that an infrequent dosing interval may be effective for sensitive bacteria.
\end{abstract}

Key words: Biologic marker, Caretta caretta, loggerhead sea turtle, oxytetracycline, pharmacokinetics.

\section{INTRODUCTION}

Oxytetracycline has long been used as a biologic marker to label bone for aging and other studies. ${ }^{710,12}$ Like other tetracyclines, oxytetracycline is incorporated into mineralizing tissue, including bone, teeth and otoliths, and fluoresces under ultraviolet light, making it possible to detect in cross sections those parts of the structure that were min-

From the Environmental Medicine Consortium, North Carolina State University, 4700 Hillsborough Street, Raleigh, North Carolina 27606, USA (Harms, Papich); the Departments of Clinical Sciences (Harms, Ross) and Molecular and Biomedical Sciences (Papich), College of Veterinary Medicine, 4700 Hillsborough Street, Raleigh, North Carolina 27606, USA; North Carolina State University Center for Marine Sciences and Technology, 303 College Circle, Morehead City, North Carolina 28557, USA (Harms); Animal Programs, Disney's Epcot The Living Seas, EC Trl. W-251, P.O. Box 10,000, Lake Buena Vista, Florida 32830-1000, USA (Stamper); National Marine Fisheries Service, National Oceanic and Atmospheric Administration Galveston Laboratory, Galveston, Texas 77551, USA (Rodriguez); and the National Marine Fisheries Service, National Oceanographic and Atmospheric Administration Beaufort Laboratory, 101 Pivers Island Road, Beaufort, North Carolina 28516, USA (Hohn). Present address (Ross): Ocean State Veterinary Specialists, 3307 South Country Trail, East Greenwich, Rhode Island 02818, USA. Correspondence should be directed to Dr. Harms. eralizing at the time of administration. The fluorescent oxytetracycline band can be used to establish a known point in the osseous timeline to determine whether or not subsequent growth marks are annual. This procedure has been performed with sea turtle humeri to validate the use of skeletochronology for aging estimates but with some debate over effects of noncyclic events, extended periods in stable tropical environments, and bone-remodeling patterns on formation and retention of annuli. ${ }^{1,4,20}$ Although an oxytetracycline dose effective in marking sea turtle bone has been published ( 25 $\mathrm{mg} / \mathrm{kg}$ i.m.), ${ }^{1,420}$ the pharmacokinetics of that dose have not been established in any sea turtle species.

Along with its application in skeletal marking, oxytetracycline has been used as an antimicrobial medication for decades. This drug has been used in sea turtles, although safe and effective antibacterial dosage regimens are poorly established for many reptiles, including sea turtles. Most dosage regimens are empirical and are based on extrapolations from other species. Differences in antibiotic disposition by reptiles and by mammals, and even by different species of reptiles, makes cross-species extrapolation unreliable. ${ }^{18}$ Pharmacokinetic studies on four antimicrobial drugs and one anthelmintic drug, ceftazidime, florfenicol, itraconazole, fluconazole, and praziquantel, respectively, have been reported for sea turtles. ${ }^{17,22,29,30}$ Ceftazidime and fluconazole are excreted by the kidneys primarily by 
glomerular filtration in mammals, ${ }^{26,31}$ and these drugs exhibited prolonged plasma half-lives in sea turtles as compared with mammals, although there was considerable difference between their elimination rates in sea turtles. The plasma half-life for ceftazidime was determined to be $20 \mathrm{hr}$ and a q 3 day dosing regimen was recommended, whereas for fluconazole it was $132 \mathrm{hr}$ and a q 5 day dosing regimen was recommended. Oxytetracycline is also excreted by glomerular filtration in the kidneys in mammals. ${ }^{26}$ In American alligators (Alligator mississipiensis), therapeutic serum concentrations were still present 7 days after dosing at $10 \mathrm{mg} / \mathrm{kg}$ i.m. ${ }^{14}$ Thus, there was good reason to suspect that therapeutic concentrations of oxytetracycline could also be maintained for a comparatively long period in sea turtles. Prolonged therapeutic concentrations would make it useful as a presurgical prophylactic antibiotic for applications in which wild sea turtles are captured for research purposes, are released shortly after the surgical procedure (e.g., laparoscopic sexing ${ }^{2}$ or fat biopsy ${ }^{19}$ ), and are not available for repeat doses. Sea turtles so treated would also have been bone marked for potential skeletochronology study in the event of postmortem recovery at a later date, resulting in a dual-purpose use of single oxytetracycline treatments.

Oxytetracycline has activity against such gramnegative bacteria as Vibrio spp., Pseudomonas spp., and Aeromonas spp., ${ }^{26,31}$ which are often associated with morbidity and mortality of sea turtles. ${ }^{8}$ Resistance can be problematic though, particularly with Staphylococcus spp., Streptococcus spp., Pseudomonas spp., Escherichia coli, Klebsiella spp., Bacteroides spp., Enterobacter spp., and Proteus spp. ${ }^{26}$ Oxytetracycline is also active against Nocardia spp., Chlamydia/Chlamydophila spp., Rickettsia spp., Mycoplasma spp., and spirochetes. ${ }^{5,26,31}$ Of these, a Nocardia sp. has been reported as an opportunistic pathogen in a hypothermic-stunned Kemp's ridley sea turtle (Lepidochelys kempii). ${ }^{11}$ Similarly, a Chlamydia sp. was reported to cause epizootic mortality in juvenile green sea turtles (Chelonia mydas) in aquaculture. ${ }^{16}$ Although not yet reported in sea turtles, rickettsial and mycoplasmal organisms have been increasingly reported from aquatic species (e.g., Piscirickettsia spp. in fish $^{23}$ and Mycoplasma alligatoris in crocodilians ${ }^{3,27}$ ) and may eventually be found as sea turtle pathogens. This study examines oxytetracycline pharmacokinetics after single i.v. and i.m. dose injections in juvenile loggerhead sea turtles (Caretta caretta) to characterize effective clinical dosing regimens. This application, along with oxytetracy- cline's biologic marker characteristic, makes the drug a good candidate for application in sea turtles.

\section{MATERIALS AND METHODS}

\section{Subjects and sample collection}

Twenty 2-yr-old juvenile loggerhead sea turtles at the National Marine Fisheries Service, Galveston Laboratory, were studied in August 2002. Before the drug trial, each animal was weighed to the nearest $20 \mathrm{~g}$, measured in straight carapace length (SCL) and straight carapace width (SCW) to the nearest centimeter, examined visually, and bled for packed cell volume and total solids determination. As previously described, ${ }^{15}$ turtles were housed individually in circular vinyl-coated wire mesh cages, 76-cm diameter by $45-\mathrm{cm}$ water depth, lined with high-impact sytrene sheeting. Cages were suspended in 5,775-L raceways, 14 per raceway. Seawater was pumped from the Gulf of Mexico, filtered through well points, and particulates were allowed to settle out before adding water to the raceways. Water was changed $100 \%$ daily in the morning. The water temperature was $28.5-30.0^{\circ} \mathrm{C}$. Turtles were fed Purina Aquamax Grower 500 3/16-inch floating pellets (PMI Nutrition International, LLC, Brentwood, Missouri 63116 , USA) at $1 \%$ of body weight per day divided into two daily feedings.

The turtles were evenly divided into two groups of 10 in each of two raceways, with experimental protocols commencing on two different days to facilitate sampling. Within each raceway group, the 10 turtles were divided in alternating order into i.v. and i.m. treatment groups of 5 each, for a total of 10 turtles in each i.v. and i.m. treatment groups. Each animal received a single dose of oxytetracycline (Liquamycin LA-200, Pfizer Animal Health, Exton, Pennsylvania 19341, USA; $25 \mathrm{mg} / \mathrm{kg}$ ) by way of a 22-ga needle attached to a 3-ml syringe. Intravenous doses were administered in the left cervical sinus, and i.m. doses were injected into the left deltoid muscle.

Blood collection sites alternated between right and left dorsal cervical sinuses (external jugular veins) at $-24 \mathrm{hr}$ before and $0.5,1.5,3,6,12,24$, $48,96,120$, and $240 \mathrm{hr}$ after injection. One additional untreated turtle in raceway 1 and one additional untreated turtle in raceway 2 were sampled at 72 and $48 \mathrm{hr}$, respectively, to assess potential for uptake of excreted oxytetracycline from the water. Approximately, $0.5 \mathrm{ml}$ of blood was collected each time using a $3-\mathrm{ml}$ syringe with a 22 -ga needle. The syringe and needle interiors were rinsed before use with $0.1 \mathrm{ml}$ of $1,000 \mathrm{IU} / \mathrm{ml}$ sodium heparin solution (Elkins-Sinn, Inc., Cherry Hill, New Jersey 08003, 
USA) as an anticoagulant. Blood was placed into polyethylene microcentrifuge tubes (Fisher Scientific Company, Pittsburgh, Pennsylvania 15219, USA), which were capped and immediately submerged in ice water. The blood was then centrifuged to harvest approximately $0.3 \mathrm{ml}$ of plasma, which was placed in cryovials using micropipets. The tubes were capped and stored at $-20^{\circ} \mathrm{C}$ until high-performance liquid chromatography (HPLC) analysis.

\section{Oxytetracycline analysis}

Plasma samples were analyzed for oxytetracycline by adapting an HPLC method developed for analysis of doxycycline. ${ }^{6}$ The apparatus consisted of a pump (Waters Model 600 Pump, Millipore Corp., Milford, Massachusetts 01757, USA), autosampler (Agilent Technologies Series 1100 Autosampler, Agilent Technologies, Wilmington, Delaware 19810, USA), variable-wavelength UV detector (Agilent Technologies 1100 Series VWD, Agilent Technologies), and computer for data collection and analysis (Agilent 1100 series ChemStation software running on Windows 98). The column was a $4.6-\mathrm{mm}$ by $15-\mathrm{cm}$ Zorbax SBC8 (Part \# 883975906, MAC-MOD Analytical Inc., Chadds Ford, Pennsylvania 19317, USA) kept at $40^{\circ} \mathrm{C}$. A guard column consisting of a Zorbax SBC8 (MAC-MOD Analytical Inc.) was used.

HPLC conditions: Oxytetracycline was eluted with a mobile phase consisting of $70 \%$ distilled water, $20 \%$ acetonitrile, and $10 \%$ methanol. To each liter of mobile phase, $6.84 \mathrm{~g}$ of oxalic acid was added $(0.1 \mathrm{M})$. The mobile phase was filtered and degassed before use. The mobile phase flow rate was $1.0 \mathrm{ml} / \mathrm{min}$, and oxytetracycline was detected at a wavelength of $350 \mathrm{~nm}$. The column temperature was kept at a constant $40^{\circ} \mathrm{C}$.

Preparation of plasma calibration curve: Stock solutions of $1 \mathrm{mg} / \mathrm{ml}$ oxytetracycline were prepared by dissolving a pure reference standard of oxytetracycline in distilled water. These stock solutions were kept refrigerated in a tightly sealed vial. Spiking solutions for the calibration curve were prepared by diluting the stock solution with distilled water to produce solutions of $1,000-2.5 \mu \mathrm{g} / \mathrm{ml}$. To $90 \mu \mathrm{l}$ blank (unfortified) plasma, $10 \mu \mathrm{l}$ of the spiking solution was added to produce nine calibration plasma samples containing 10.0-0.0195 $\mu \mathrm{g} / \mathrm{ml}$. Plasma obtained from turtles before treatment was used as a blank. A new calibration curve was prepared for each day's samples. For the calibration curve to be accepted, it had to be linear with an $r^{2}$ value of at least 0.99 , and the calibration standards had to be backcalculated to within $15 \%$ of the true value.

Preparation of plasma samples: The samples from the study as well as the calibration plasma samples were prepared by mixing $100 \mu$ l of plasma with $100 \mu \mathrm{l}$ of a releasing agent that consisted of $20 \%$ acetonitrile, $2 \%$ phosphoric acid, and $78 \%$ distilled water, vortexed for $10 \mathrm{sec}$. This admixture was pipetted into 10,000 nominal molecular weight limit centrifugal filter units (Ultrafree-MC Centrifugal Filter Units, Millipore Corp.) vortexed briefly and centrifuged for $30 \mathrm{~min}$ at $14,000 \mathrm{rpm}$ at room temperature. The clear filtrate was transferred to an HPLC injection vial and $50 \mu \mathrm{l}$ was injected onto the HPLC column.

Calculations from the assay: With these conditions, the retention time for elution of oxytetracycline was approximately $2.7 \mathrm{~min}$. Unknown concentrations were calculated from the response milliaborbance units (mAU) using the calibration curve. Replicates of spiked plasma samples were analyzed to measure precision and accuracy. Replicates of blank plasma samples from untreated animals were used to determine the limit of detection (LOD). The LOD was defined a priori as three times the baseline noise. The limit of quantification (LOQ) was approximately $0.02 \mu \mathrm{g} / \mathrm{ml}$.

\section{Pharmacokinetic analysis}

Plasma drug concentrations after i.v or i.m. administration were plotted semilogarithmically for analysis. Analysis of curves and pharmacokinetic modeling were performed using a commercial pharmacokinetic program (WinNonlin Version 4.0, Pharsight Corporation, Mountain View, California 94040 , USA). A weighting factor of $1 /$ (predicted $\mathrm{Y})^{2}$ was used for pharmacokinetic analysis, where $\mathrm{Y}$ is the plasma concentration.

For the i.v. data, compartmental pharmacokinetic analysis was performed. The most appropriate pharmacokinetic compartmental model was determined by visual examination of the curves produced by predicted models, by using Akaike's information criterion (AIC), in which the best model is determined to be the one with the lowest (minimum) AIC, ${ }^{33}$ and by examination of residual plots. AIC was calculated by an equation that takes into account the weighting factor, the residual sum of squares (SS), and the number of parameters in the model. It favors the simplest model when the residual SS are similar between two models. After it was determined which model was the best fit for the data (i.e., mono-, bi-, or triexponential function), elimination rates, half-lives, and intercepts were determined from exponents and coefficients of the 
best fit to an equation using weighted nonlinear least squares regression analysis.

The general form for the formula for a multicompartment analysis was

$$
\mathrm{C}=\mathrm{A}_{n} \mathrm{e}^{-\lambda n t}
$$

where $\mathrm{C}$ is the plasma concentration, $\mathrm{A}_{n}$ is the $\mathrm{y}$ axis intercept, $\mathrm{e}$ is the base of the natural logarithm, $n$ is the number of compartments, $\mathrm{t}$ is time after dosing, and $\lambda \mathrm{n}$ is the rate constant. For the twocompartment, biexponential model, the corresponding equation was

$$
\mathrm{C}=\mathrm{Ae}^{-\alpha t}+\mathrm{B}^{-\beta t}
$$

where $\mathrm{C}$ is the plasma drug concentration at time $\mathrm{t}, \mathrm{A}$ and $\mathrm{B}$ are the $\mathrm{y}$-axis intercepts for the distribution and elimination phases of the curve, respectively, $\alpha$ and $\beta$ are the rate constants for the distribution and elimination phases of the curve, respectively, and $\mathrm{e}$ is the base of the natural logarithm. The elimination half-life $\left(t_{1 / 2}\right)$ is estimated from the relationship: $t_{1 / 2}=\ln 0.5 /$ rate constant. The corresponding equation for a three-compartment model was

$$
\mathrm{C}=\mathrm{Ae}^{-\alpha t}+\mathrm{Be}^{-\beta t}+\mathrm{Ce}^{-\gamma t}
$$

where $\mathrm{C}$ is the plasma drug concentration at time $\mathrm{t}, \mathrm{A}, \mathrm{B}$, and $\mathrm{C}$ are the $\mathrm{y}$-axis intercepts for the first and second distribution phases and elimination phase of the curve, respectively, and $\alpha, \beta$, and $\gamma$ are the rate constants for the first and second distribution phases and elimination phase of the curve, respectively. Other compartmental pharmacokinetic parameters are calculated according to published formulae. ${ }^{9}$

For the i.m. data, there was not a unique compartmental model that was consistent for analyzing these concentrations. Therefore, concentrations from the i.m. dose were analyzed using noncompartmental analysis (NCA). For the purpose of making comparisons of parameters between i.m. and i.v. administration, the i.v. data also were analyzed using noncompartmental methods.

The area under the plasma concentration versus time curve (AUC) from time 0 to the last measured concentration (defined by the LOQ) was calculated using the log-linear trapezoidal method. The AUC from time 0 to infinity was calculated by adding the terminal portion of the curve, estimated from the relationship $\mathrm{Cn} / \mathrm{\lambda z}$, to the $\mathrm{AUC}_{0-\mathrm{Cn}}$, where $\lambda$ is the terminal slope of the curve, and $\mathrm{Cn}$ is the last measured concentration point. Values for the maximum plasma concentration after dosing $\left(\mathrm{C}_{0}\right.$ for i.v. or $\mathrm{C}_{\mathrm{MAX}}$ for i.m.) and time to maximum plasma concentration $\left(\mathrm{T}_{\mathrm{MAX}}\right)$ were taken directly from the data.
Mean residence time (MRT) was calculated from the area under the moment curve from zero to infinity (AUMC) and AUC. For the i.v. dose, apparent volume of distribution using the area method $\left(\mathrm{VD}_{\mathrm{AREA}}\right)$, apparent volume of distribution at steady-state (VDss), and systemic clearance (CL) were calculated according to published methods. ${ }^{9}$ Systemic availability (\%F) from the i.m. dose was calculated from the following formula: $\% \mathrm{~F}=$ $\mathrm{AUC}_{\mathrm{IM}} / \mathrm{AUC}_{\mathrm{IV}} \times 100$. Clearance and apparent volume of distribution corrected for absorption, CL/F and $\mathrm{VD}_{\mathrm{AREA}} / \mathrm{F}$, respectively, also were calculated from the i.m. data.

Pharmacokinetic estimates from the single-dose study were used to simulate a multidose regimen (WinNonlin 4.0). ${ }^{9}$ Target minimum plasma concentrations in the multidose simulation were 4,2 , and $1 \mu \mathrm{g} / \mathrm{ml}$, representing the minimum inhibitory concentration (MIC) at which microorganisms reportedly pathogenic to sea turtles are generally considered susceptible, and two lesser concentrations were demonstrated to be effective for more susceptible microbes. ${ }^{13,31}$ The multidose simulations were not tested experimentally.

Statistical differences between i.m. and i.v. groups in weight, length, packed cell volume (PCV), total solids (TS), and noncompartmental pharmacokinetic parameters $\mathrm{C}_{\operatorname{MAX}}$ (i.m.) or $\mathrm{C}_{0}$ (i.v.), elimination rate constant, CL, AUC, VD, and MRT were tested by Student's $t$-test for independent samples (JMP, SAS Institute, Cary, North Carolina 27513, USA). Potential effects of weight on pharmacokinetic parameters $\left(\mathrm{C}_{\mathrm{MAX}}\right.$ or $\mathrm{C}_{0}, \mathrm{CL}$, AUC, $\mathrm{VD}$, and MRT) were tested for i.m. and i.v. groups separately by least squares linear regression. The level of significance was $P<0.05$.

\section{RESULTS}

The mean turtle weight was $7.98 \pm 0.78 \mathrm{~kg}$, with a SCL of $39 \pm 1.4 \mathrm{~cm}$ and SCW of $32 \pm 1.2 \mathrm{~cm}$. The mean packed cell volume was $27 \pm 2.8 \%$, and mean total solids was $19 \pm 2 \mathrm{~g} / \mathrm{L}$. There were no differences between treatment groups in weight, SCL, SCW, PCV, or TS $(P>0.05)$. No abnormalities were noted on physical examination, and no adverse effects were noted with respect to injection site, flipper movement, activity, or food consumption during the course of the investigation.

Oxytetracycline HPLC analysis provided a rapid and sensitive method for measuring concentrations using a small volume of plasma. The calibration curve was linear from 0.0195 to $10 \mu \mathrm{g} / \mathrm{ml}$. All the samples measured in this study were above the LOQ. The precision and accuracy of the assay were within acceptable limits. No oxytetracycline was 


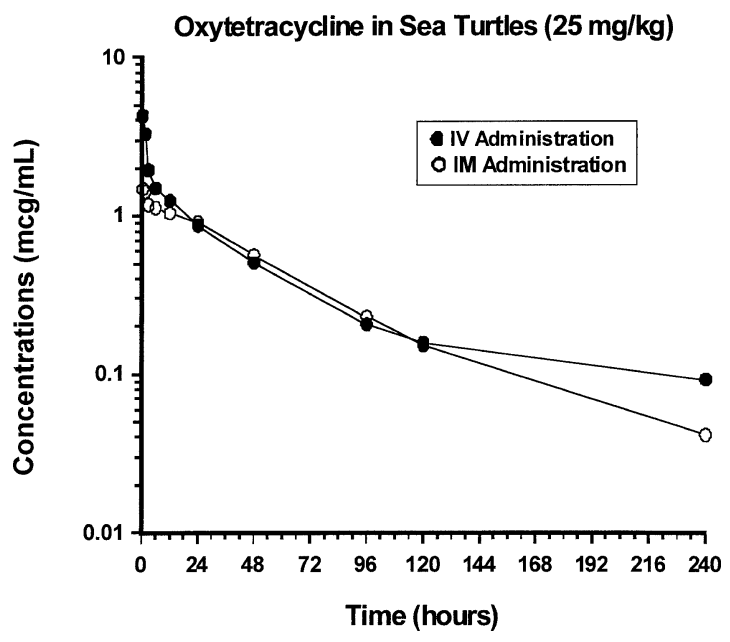

Figure 1. Plasma concentrations of oxytetracycline in turtles after administration of $25 \mathrm{mg} / \mathrm{kg}$ i.v. (solid circle) or i.m. (open circle). Each point represents the mean of 10 concentrations. Variances for mean values are shown in Table 1.

detected in the plasma of untreated controls sharing the raceways with treated sea turtles.

The results of the plasma analysis are shown in Figure 1 and Tables 1-3. The absorption from the i.m. injection was high as shown by the rapid and high peak concentrations. The mean systemic avail- ability was $91.8 \%$. The compartmental analysis for i.v. data (Table 3) produced a three-compartment model for nine animals as the best fit. In one animal (C19) the best fit was with a two-compartment model. Only those values that corresponded to the three-compartment model were averaged with the others in Table 3. One animal (C7) clearly was an outlier as shown by the long terminal half-life. There were two terminal points for this animal's curve that produced a shallow slope, resulting in an extremely long half-life. The data from this animal were not averaged with the other nine. Table 2 shows the results from a NCA of the i.v. and i.m. data in which assumptions of one, two, or three compartments were not made. Data from animal C7 and C19 were not considered outliers in this analysis (although their values made up the extreme ends of each range), and their data were averaged with the other animals.

MRT $(62.75 \pm 5.58 \mathrm{hr}$ for i.v., $70.02 \pm 5.25 \mathrm{hr}$ for i.m.; $P=0.077$ ) was significantly different between i.m. and i.v. groups. The initial plasma concentrations $\left(\mathrm{C}_{\mathrm{MAX}}\right.$ for i.m. $1.57 \pm 0.30 \mu \mathrm{g} / \mathrm{ml}$; and $\mathrm{C}_{0}$ for i.v. $5.50 \pm 1.00 \mu \mathrm{g} / \mathrm{ml}$ ) were significantly different between treatments, but this may have been caused by the route of administration. Parameters exhibiting no significant difference were AUC, CL, and VD. Though CL and VD from the

Table 1. Mean concentrations (in $\mu \mathrm{g} / \mathrm{ml}$ ) of oxytetracycline in loggerheads after administration of $25 \mathrm{mg} / \mathrm{kg}$.

\begin{tabular}{|c|c|c|c|c|c|c|c|c|}
\hline Time (hr) & $\mathrm{N}$ & $\bar{x} \pm \mathrm{SD}$ & SE & Min & Median & Max & Range & $\mathrm{CV} \%$ \\
\hline \multicolumn{9}{|c|}{ Intramuscular administration } \\
\hline 0.5 & 10 & $1.4763 \pm 0.3667$ & 0.1160 & 0.9737 & 1.4223 & 2.2838 & 1.3101 & 24.838 \\
\hline 1.5 & 10 & $1.4110 \pm 0.1304$ & 0.0412 & 1.1560 & 1.4032 & 1.5913 & 0.4354 & 9.2420 \\
\hline 3 & 10 & $1.1638 \pm 0.1398$ & 0.0442 & 0.9692 & 1.1488 & 1.4216 & 0.4523 & 12.010 \\
\hline 6 & 10 & $1.1155 \pm 0.1344$ & 0.0425 & 0.8771 & 1.1185 & 1.2835 & 0.4063 & 12.045 \\
\hline 12 & 10 & $1.0330 \pm 0.0875$ & 0.0277 & 0.9019 & 1.0491 & 1.1647 & 0.2627 & 8.4700 \\
\hline 24 & 10 & $0.9053 \pm 0.0619$ & 0.0196 & 0.7787 & 0.8982 & 0.9859 & 0.2072 & 6.8331 \\
\hline 48 & 10 & $0.5613 \pm 0.0538$ & 0.0170 & 0.5119 & 0.5592 & 0.6977 & 0.1858 & 9.5787 \\
\hline 96 & 10 & $0.2276 \pm 0.0256$ & 0.0081 & 0.1958 & 0.2184 & 0.2643 & 0.0686 & 11.242 \\
\hline 120 & 10 & $0.1511 \pm 0.0226$ & 0.0071 & 0.1336 & 0.1402 & 0.2031 & 0.0695 & 14.953 \\
\hline 240 & 10 & $0.0411 \pm 0.0085$ & 0.0027 & 0.0245 & 0.0420 & 0.0570 & 0.0325 & 20.725 \\
\hline \multicolumn{9}{|c|}{ Intravenous administration } \\
\hline 0.5 & 10 & $4.2717 \pm 0.5212$ & 0.1648 & 3.0272 & 4.3447 & 5.1412 & 2.1141 & 12.200 \\
\hline 1.5 & 10 & $3.2757 \pm 2.2131$ & 0.6998 & 2.2718 & 2.5602 & 9.5441 & 7.2722 & 67.560 \\
\hline 3 & 10 & $1.9332 \pm 0.2037$ & 0.0644 & 1.4862 & 1.9763 & 2.1484 & 0.6622 & 10.534 \\
\hline 6 & 10 & $1.4839 \pm 0.1812$ & 0.0573 & 1.1427 & 1.5126 & 1.8492 & 0.7065 & 12.209 \\
\hline 12 & 10 & $1.2323 \pm 0.1389$ & 0.0439 & 1.0231 & 1.2298 & 1.4808 & 0.4577 & 11.270 \\
\hline 24 & 10 & $0.8637 \pm 0.1169$ & 0.0370 & 0.6594 & 0.8780 & 1.0742 & 0.4148 & 13.533 \\
\hline 48 & 10 & $0.5002 \pm 0.0724$ & 0.0229 & 0.4239 & 0.4856 & 0.6647 & 0.2408 & 14.468 \\
\hline 96 & 10 & $0.2046 \pm 0.0429$ & 0.0136 & 0.1388 & 0.1952 & 0.2973 & 0.1585 & 20.973 \\
\hline 120 & 10 & $0.1563 \pm 0.0538$ & 0.0170 & 0.0746 & 0.1530 & 0.2837 & 0.2091 & 34.438 \\
\hline 240 & 10 & $0.0916 \pm 0.1662$ & 0.0526 & 0.0311 & 0.0379 & 0.5643 & 0.5333 & 181.43 \\
\hline
\end{tabular}


Table 2. Pharmacokinetic parameters from noncompartmental analysis for oxytetracycline in loggerheads after administration of $25 \mathrm{mg} / \mathrm{kg}$ i.v. or i.m. C1-C20 refers to individual sea turtle identifications.

\begin{tabular}{|c|c|c|c|c|c|}
\hline Intravenous & Units & $\mathrm{C} 1$ & $\mathrm{C} 3$ & $\mathrm{C} 5$ & $\mathrm{C} 7$ \\
\hline Kel & $1 / \mathrm{hr}$ & 0.01 & 0.01 & 0.01 & 0.01 \\
\hline Kel half-life & $\mathrm{hr}$ & 64.62 & 52.45 & 57.54 & 80.51 \\
\hline $\mathrm{C}_{0}$ & $\mu \mathrm{g} / \mathrm{ml}$ & 5.24 & 5.86 & 5.91 & 5.62 \\
\hline AUC (0 to $\mathrm{Cn})$ & $\mathrm{hr} \times \mu \mathrm{g} / \mathrm{ml}$ & 71.15 & 85.81 & 80.06 & 68.72 \\
\hline AUC (0 to Inf) & $\mathrm{hr} \times \mu \mathrm{g} / \mathrm{ml}$ & 74.05 & 88.60 & 82.74 & 72.49 \\
\hline AUC \% extrapolated & $\%$ & 3.91 & 3.14 & 3.24 & 5.20 \\
\hline $\mathrm{VD}_{\text {AREA }}$ & $\mathrm{ml} / \mathrm{kg}$ & $31,475.3$ & $21,352.0$ & $25,083.3$ & $40,057.6$ \\
\hline CL & $\mathrm{ml} / \mathrm{hr} / \mathrm{kg}$ & 337.61 & 282.18 & 302.15 & 344.85 \\
\hline AUMC & $\mathrm{hr}^{2} \times \mu \mathrm{g} / \mathrm{ml}$ & $4,230.24$ & $5,349.85$ & $4,683.96$ & $4,413.72$ \\
\hline MRT (0 to Inf) & $\mathrm{hr}$ & 57.13 & 60.38 & 56.61 & 60.88 \\
\hline VDss & $\mathrm{ml} / \mathrm{kg}$ & $19,286.1$ & $17,039.0$ & $17,104.3$ & $20,995.9$ \\
\hline Intramuscular & Units & $\mathrm{C} 2$ & $\mathrm{C} 4$ & C6 & $\mathrm{C} 8$ \\
\hline Kel & $1 / \mathrm{hr}$ & 0.01 & 0.01 & 0.01 & 0.01 \\
\hline Kel half-life & $\mathrm{hr}$ & 46.83 & 68.18 & 54.30 & 67.14 \\
\hline $\mathrm{T}_{\mathrm{MAX}}$ & $\mathrm{hr}$ & 0.50 & 1.50 & 0.50 & 0.50 \\
\hline $\mathrm{C}_{\mathrm{MAX}}$ & $\mu \mathrm{g} / \mathrm{ml}$ & 1.39 & 1.50 & 1.59 & 1.70 \\
\hline AUC (0 to $\mathrm{Cn})$ & $\mathrm{hr} \times \mu \mathrm{g} / \mathrm{ml}$ & 69.29 & 71.52 & 78.72 & 74.67 \\
\hline AUC (0 to inf) & $\mathrm{hr} \times \mu \mathrm{g} / \mathrm{ml}$ & 70.94 & 75.65 & 81.47 & 78.72 \\
\hline AUC \% extrapolated & $\%$ & 2.33 & 5.47 & 3.37 & 5.14 \\
\hline $\mathrm{VD} / \mathrm{F}$ & $\mathrm{ml} / \mathrm{kg}$ & $23,808.4$ & $32,506.1$ & $24,039.1$ & $30,759.5$ \\
\hline $\mathrm{CL} / \mathrm{F}$ & $\mathrm{ml} / \mathrm{hr} / \mathrm{kg} \mathrm{hr} \times \mathrm{hr} \times \mu \mathrm{g} / \mathrm{m}$ & 352.40 & 330.46 & 306.87 & 317.58 \\
\hline AUMC (0 to inf) & 1 & $4,280.52$ & $5,398.24$ & $5,226.48$ & $5,508.02$ \\
\hline MRT & $\mathrm{hr}$ & 60.34 & 71.36 & 64.15 & 69.97 \\
\hline
\end{tabular}

${ }^{a} \mathrm{C}_{0}$, initial plasma concentration (i.v.); AUC, area under the plasma concentration vs. time curve; VD ${ }_{\mathrm{AREA}}$, apparent volume of distribution using the area method; CL, systemic clearance; AUMC, area under the first moment curve; MRT, mean residence time; VDss, apparent volume of distribution at steady state; $\mathrm{T}_{\mathrm{MAX}}$, time to maximum plasma concentration; and $\mathrm{C}_{\mathrm{MAX}}$, maximum plasma concentration (i.m.); Kel, elimination rate constant; VD/F, volume of distribution (area method) corrected for systemic availability; CL/ F, systemic clearance corrected for systemic availability.

non-i.v. route are calculated as $\mathrm{CL} / \mathrm{F}$ and $\mathrm{VD} / \mathrm{F}$, respectively, they were compared with the i.v. route in this analysis because nearly complete absorption was assumed (that is, the value of $\mathrm{F}$ approached $100 \%$.) Although the MRT difference was statistically different between routes of administration, pharmacokinetically the difference was minor. Within the size range of turtles used in this study $(6.40-9.12 \mathrm{~kg})$, weight did not correlate with any of the noncompartmental pharmacokinetic parameters analyzed (least squares linear regression, $P>$ $0.05)$ except for a loose positive correlation with MRT in the i.m. group $\left(R^{2}=0.56, P=0.013\right)$. The $\mathrm{T}_{\mathrm{MAX}}$ for i.m. administration was $1.0 \pm 0.53 \mathrm{hr}$.

Simulation of multidose protocols designed to achieve minimum plasma concentrations of 1 or 2 $\mu \mathrm{g} / \mathrm{ml}$ resulted in dosing regimens of $41 \mathrm{mg} / \mathrm{kg}$ i.m. loading dose followed by $21 \mathrm{mg} / \mathrm{kg}$ i.m. q $72 \mathrm{hr}$ and $82 \mathrm{mg} / \mathrm{kg}$ i.m. loading dose followed by $42 \mathrm{mg} /$ kg i.m. q 72 hr, respectively (Fig. 2). The dosing regimen to achieve minimum plasma concentra- tions of $4 \mu \mathrm{g} / \mathrm{ml}$ required a loading dose of 150 $\mathrm{mg} / \mathrm{kg}$ i.m. (not shown).

\section{DISCUSSION}

The HPLC assay described was reliable and accurate. The assay had a sufficiently low detection limit that could accommodate the low volume of plasma $(100 \mu \mathrm{l})$ used, and it would also be suitable for smaller animals. All the concentrations measured in this study were above the minimum LOQ.

No adverse effects were noted with a single 25 $\mathrm{mg} / \mathrm{kg}$ i.v. or i.m. dose of oxytetracycline in these twenty loggerheads. However, oxytetracycline at 10 $\mathrm{mg} / \mathrm{kg}$ i.m. q 5 days in a single Kemp's ridley turtle treated for Nocardia sp. was associated anecdotally with ventral erythema and skin exfoliation after 2 wk, which resolved after discontinuing oxytetracycline. ${ }^{11}$

The compartmental analysis produced a threecompartmental model for the i.v. administration, except for one animal (C19). The three-compart- 
Table 2. Extended.

\begin{tabular}{|c|c|c|c|c|c|c|c|}
\hline C9 & $\mathrm{C} 11$ & $\mathrm{C} 13$ & $\mathrm{C} 15$ & $\mathrm{C} 17$ & C19 & Mean & SD \\
\hline 0.01 & 0.01 & 0.01 & 0.01 & 0.01 & 0.01 & 0.01 & 0.00 \\
\hline 67.32 & 62.82 & 58.85 & 70.74 & 71.71 & 54.19 & 64.08 & 8.75 \\
\hline 5.41 & 5.38 & 7.01 & 6.01 & 5.58 & 3.03 & 5.50 & 1.00 \\
\hline 83.17 & 79.56 & 88.52 & 82.10 & 76.10 & 86.66 & 80.19 & 6.55 \\
\hline 87.40 & 83.03 & 91.70 & 87.31 & 81.12 & 106.60 & 85.50 & 9.62 \\
\hline 4.84 & 4.18 & 3.46 & 5.97 & 6.19 & 18.71 & 5.89 & 4.63 \\
\hline $27,782.2$ & $27,289.9$ & $23,148.1$ & $29,222.8$ & $31,885.2$ & $18,333.0$ & $27,563.0$ & $6,167.9$ \\
\hline 286.04 & 301.10 & 272.63 & 286.34 & 308.18 & 234.52 & 295.56 & 31.69 \\
\hline $5,584.41$ & $5,043.41$ & $5,277.92$ & $6,169.86$ & $5,807.88$ & $7,254.59$ & $5,381.58$ & 896.14 \\
\hline 63.89 & 60.74 & 57.56 & 70.67 & 71.60 & 68.05 & 62.75 & 5.58 \\
\hline $18,276.5$ & $18,290.2$ & $15,691.4$ & $20,234.4$ & $22,064.3$ & $15,959.7$ & $18,494.2$ & $2,136.3$ \\
\hline $\mathrm{C} 10$ & $\mathrm{C} 12$ & $\mathrm{C} 14$ & $\mathrm{C} 16$ & C18 & $\mathrm{C} 20$ & Mean & SD \\
\hline 0.01 & 0.01 & 0.01 & 0.01 & 0.01 & 0.01 & 0.01 & 0.00 \\
\hline 60.54 & 65.43 & 60.12 & 65.27 & 67.55 & 63.61 & 61.90 & 6.80 \\
\hline 1.50 & 0.50 & 1.50 & 1.50 & 0.50 & 1.50 & 1.00 & 0.53 \\
\hline 1.59 & 2.28 & 1.16 & 1.48 & 1.68 & 1.34 & 1.57 & 0.30 \\
\hline 74.20 & 76.51 & 74.59 & 87.68 & 71.92 & 68.76 & 74.78 & 5.48 \\
\hline 77.40 & 80.87 & 78.60 & 93.05 & 76.16 & 72.24 & 78.51 & 6.12 \\
\hline 4.14 & 5.39 & 5.10 & 5.77 & 5.57 & 4.81 & 4.71 & 1.11 \\
\hline $28,208.2$ & $29,183.6$ & $27,588.6$ & $25,301.3$ & $31,990.9$ & $31,757.0$ & $28,514.3$ & $3,290.9$ \\
\hline 322.99 & 309.15 & 318.08 & 268.68 & 328.25 & 346.06 & 320.05 & 23.21 \\
\hline $5,100.88$ & $5,872.00$ & $5,971.91$ & $7,172.08$ & $5,566.32$ & $5,034.40$ & $5,513.08$ & 753.37 \\
\hline 65.90 & 72.61 & 75.98 & 77.08 & 73.09 & 69.69 & 70.02 & 5.25 \\
\hline
\end{tabular}

ment model is difficult to rectify physiologically, but it probably represents a rapid and slow distribution phase and a slower terminal elimination phase from a deep compartment. The high apparent volume of distribution also was indicative of a very deep compartment. The apparent VDss measured here was greater than $18 \mathrm{~L} / \mathrm{kg}$. This is not likely to be an aberrant calculation from the compartmental analysis because the NCA produced almost the same value. In domestic animals, the VDss is reported to be from 1 to $2 \mathrm{~L} / \mathrm{kg}$, except for one study in veal calves in which a VDss was reported to be greater than $18 \mathrm{~L} / \mathrm{kg}^{24,28}$ Interestingly, in the veal calf study, the investigators also identified an extended terminal phase from a three-compartment pharmacokinetic analysis. This third phase had a half-life of $93 \mathrm{hr}$ in calves. The authors proposed that the extended terminal phase could be due to continued absorption from an injection depot, which can be ruled out here for the i.v. study, slow release of oxytetracycline from deposition in bones, or enterohepatic recycling. We suspect that the slow elimination in loggerheads is more likely related to slow metabolic rate and renal clearance for tetracycline in reptiles, as has been shown to occur with other drugs. ${ }^{21,25,29}$ The deep compartment indicated by the high VDss likely represents bone deposition, reflecting the large skeletal mass of chelonians and the fact that these were well-nourished growing juveniles. Bone deposition is one of the characteristics that makes oxytetracycline useful for validating aging by skeletochronology. 1,4,20

In this study, the terminal elimination phase of oxytetracycline had a mean half-life of $66 \mathrm{hr}$ after i.v. administration. This corresponded well with the terminal half-life calculated from the noncompartmental analysis, which was 64 and $62 \mathrm{hr}$ from the i.v. and i.m. administration, respectively. In other respects, too, the compartmental analysis differed little from the noncompartmental analysis. Values for clearance, VDss, MRT, and total AUC were very close. The advantage of the compartmental analysis was that it allowed us to identify that there is a third, deep compartment, from which there is slow elimination in these turtles. The compartmental analysis also allowed us to identify intercompartmental rate constants used for dosing simulations.

The noncompartmental pharmacokinetic analysis showed that there is little difference between i.m. and i.v. administration of this formulation of oxytetracycline in loggerhead sea turtles. Except for the 


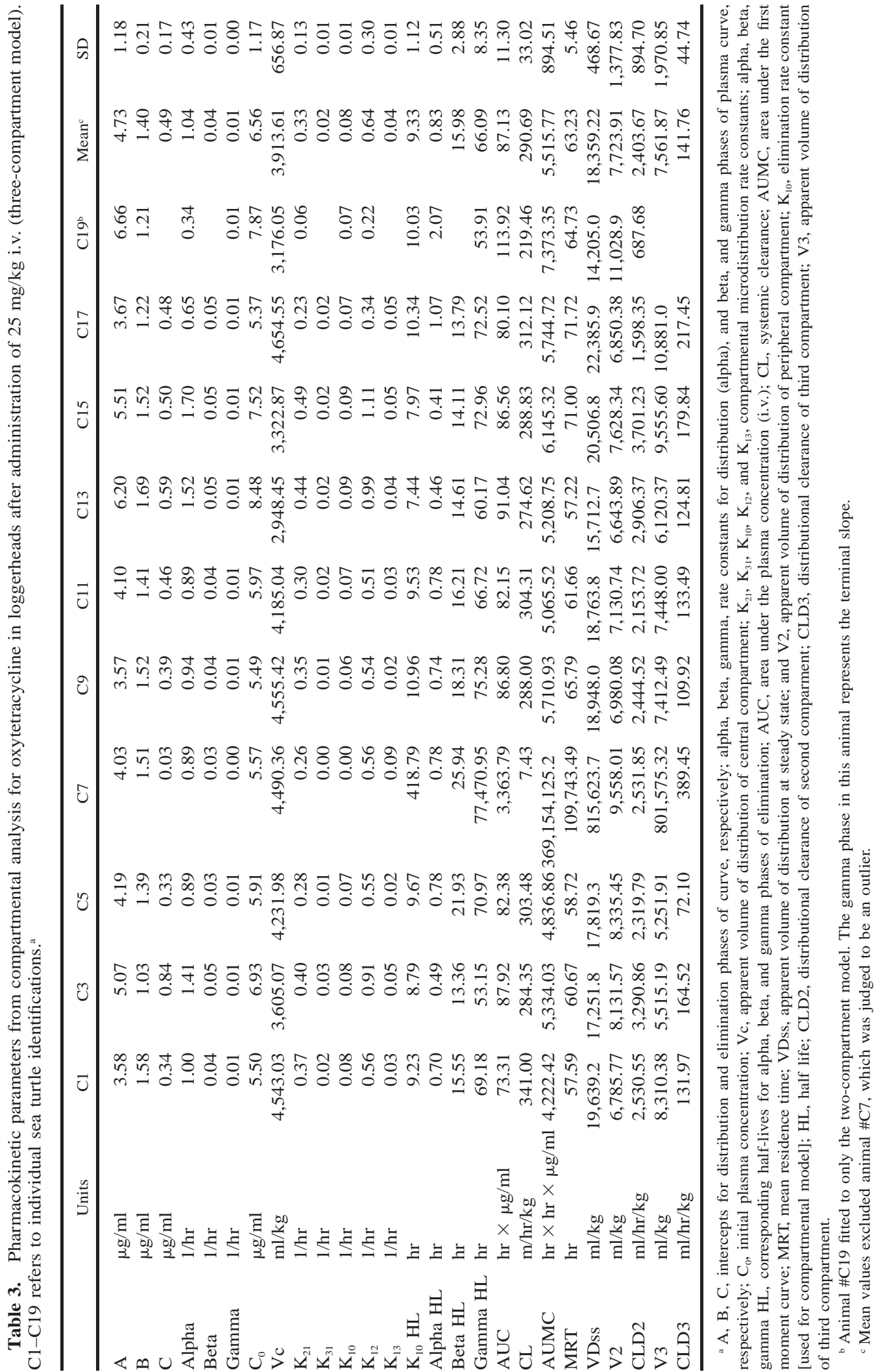


A.

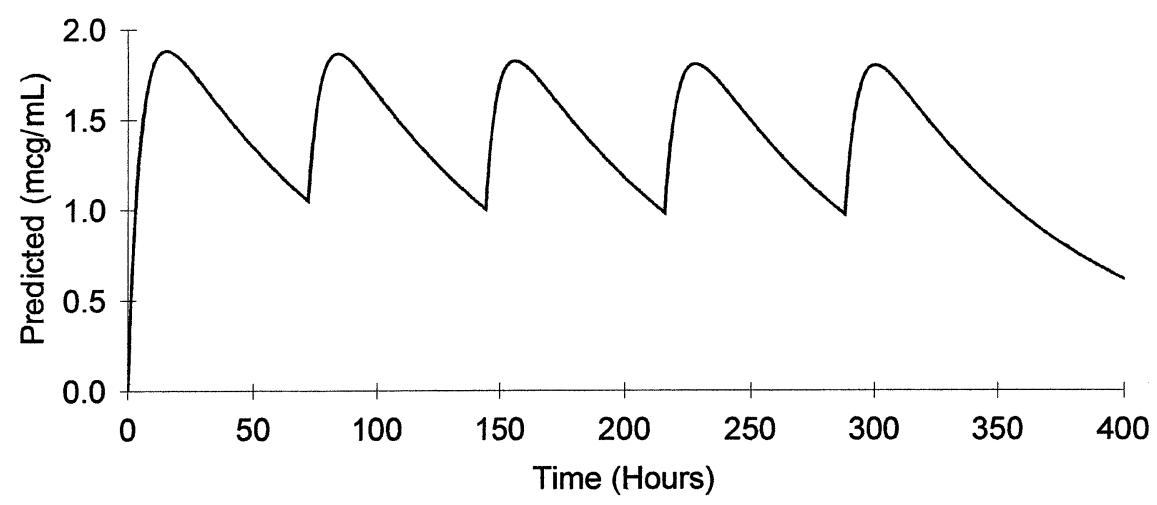

B.

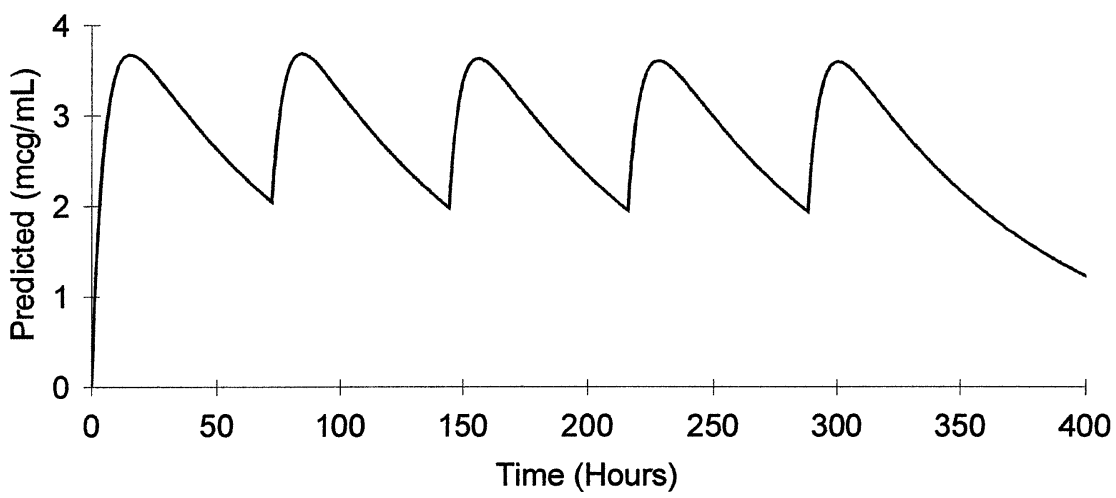

Figure 2. A. Simulation of plasma concentrations of oxytetracycline to maintain minimum concentration $\left(\mathrm{C}_{\mathrm{MIN}}\right)$ above $1.0 \mu \mathrm{g} / \mathrm{ml}$. The dosing regimen is $41 \mathrm{mg} / \mathrm{kg}$ i.m., followed by $21 \mathrm{mg} / \mathrm{kg}$ every $72 \mathrm{hr}$, i.m. $\mathrm{C}_{\mathrm{MAX}}$ in this simulation is $1.8 \mu \mathrm{g} / \mathrm{ml} ; \mathrm{C}_{\text {MIN }}$ is $0.97 \mu \mathrm{g} / \mathrm{ml}$. B. Simulation of plasma concentrations of oxytetracycline designed to maintain minimum concentration $\left(\mathrm{C}_{\mathrm{MIN}}\right)$ above $2.0 \mu \mathrm{g} / \mathrm{ml}$. Dosing regimen is $80 \mathrm{mg} / \mathrm{kg}$ i.m. followed by $42 \mathrm{mg} / \mathrm{kg}$ every $72 \mathrm{hr}$, i.m. $\mathrm{C}_{\mathrm{MAX}}$ in this simulation is $3.58 \mu \mathrm{g} / \mathrm{ml} ; \mathrm{C}_{\text {MIN }}$ is $1.93 \mu \mathrm{g} / \mathrm{ml}$.

higher initial $\mathrm{C}_{0}$ from the i.v. route compared with the $\mathrm{C}_{\mathrm{MAX}}$ from the i.m. route, these routes of administration are nearly interchangeable from a pharmacokinetic point of view. Higher initial plasma concentrations are expected from the i.v. route because it produces high instantaneous plasma concentrations without relying on uptake from the injection site. There is some divergence at the ter- minal portion of the curve (Fig. 1) between the i.v. and i.m. doses, but this difference is minimal. The variability of this time point was high (Table 1) because of variation caused by a few animals. Because Figure 1 is represented on a semilogarithmic axis, small differences at low concentrations are visually exaggerated. The bioavailability from the i.m. injection was almost complete $(>90 \%)$, with 
rapid absorption (short $\mathrm{T}_{\mathrm{MAX}}$ ). Elimination rates were essentially the same from the i.m. compared with the i.v. administration. Because this is a bacteriostatic drug, the therapeutic benefit derives from a long duration of drug plasma concentration above the MIC ( $\mathrm{T}>\mathrm{MIC})$, rather than from a brief duration at a higher plasma concentration $\left(\mathrm{C}_{\mathrm{MAX}}\right)$. Therefore, the long elimination from either route of administration is an advantage that should allow for long intervals between injections.

The only other report that we could identify in which oxytetracycline pharmacokinetics have been studied in reptiles was in alligators. ${ }^{14}$ In that study, there were mean terminal half-lives of 74 and 131 hr after i.v. and i.m. administration, respectively. There appeared to be a more sustained slow release from i.m. injection in alligators. The major difference between alligators and loggerhead sea turtles was that the apparent volume of distribution in alligators was only $0.2 \mathrm{~L} / \mathrm{kg}$ and the clearance was only $0.007 \mathrm{~L} / \mathrm{kg} / \mathrm{hr}$. The corresponding values from loggerheads in this study were $>18 \mathrm{~L} / \mathrm{kg}$ and 0.29 $\mathrm{L} / \mathrm{kg} / \mathrm{hr}$, respectively. More rapid clearance may indicate differences in metabolism or elimination between these two species. Clearly, it supports the premise that all reptiles should not be assumed to be identical when extrapolating pharmacokinetic data. ${ }^{18}$

We did not test the multidose simulations derived from single-dose pharmacokinetics. The dosing regimen required to achieve a minimum plasma concentration of $4 \mu \mathrm{g} / \mathrm{ml}$ was judged excessive for practical use, with a loading dose of $150 \mathrm{mg} / \mathrm{kg}$ i.m. Although $4 \mu \mathrm{g} / \mathrm{ml}$ is the MIC at which microorganisms are generally considered susceptible, ${ }^{31}$ lower sustained concentrations may suffice for susceptible organisms as determined by MIC sensitivity testing or for certain types of pathogens such as chlamydial or mycoplasmal organisms..$^{5,14}$ The loading doses of oxytetracycline determined here by simulation to achieve $2 \mu \mathrm{g} / \mathrm{ml}(80 \mathrm{mg} / \mathrm{kg}$ i.m.) or $1 \mu \mathrm{g} / \mathrm{ml}$ (41 mg/kg i.m.) minimum plasma concentrations for 3 days are comparable with the dose of $50-100 \mathrm{mg} / \mathrm{kg}$ s.c. q $2-3$ days determined by a pharmacokinetic study in cockatoos to maintain 1 $\mu \mathrm{g} / \mathrm{ml}$ minimum plasma concentrations and is recommended for treating chlamydiosis. ${ }^{5}$

After an i.m. dose of $25 \mathrm{mg} / \mathrm{kg}$, the plasma oxytetracycline concentration exceeded $1 \mu \mathrm{g} / \mathrm{ml}$ for less than 1 day (Fig. 1), suggesting that this dose reported for bone marking in sea turtle skeletochronology studies ${ }^{1,4,20}$ would not confer extended protection against susceptible pathogens if administered as a presurgical prophylactic antibiotic. Initial prophylaxis could still be expected, although the efficacy of a single presurgical treatment with a short-duration antibiotic in preventing iatrogenic infection in mammals is a matter of some debate, with some studies indicating a protective effect whereas others show no effect. ${ }^{32}$ The higher loading doses modeled for multidose administration appear likely to result in more extended protection (Fig. 2 ), although the effect on incorporation of oxytetracycline during bone deposition is unknown. If bone marking is not an objective in cases where presurgical prophylactic antibiotics are considered, an antibiotic with more prolonged therapeutic plasma concentrations (e.g., ceftazidime ${ }^{29}$ ) may be indicated. As in other species, systemic antimicrobial use should not be considered a substitute for good aseptic technique during surgery.

This study determined the pharmacokinetic parameters of oxytetracycline administered i.v. and i.m at a dose $(25 \mathrm{mg} / \mathrm{kg})$ previously used for bone marking in sea turtles. ${ }^{1,4,20}$ No adverse reactions were identified at that dose. A deep compartment was identified, likely representing bone deposition, although bone deposition was not assessed directly. Additional information that would be helpful in the interpretation of oxytetracycline use in skeletochronology applications would include the determination of the minimum effective dose resulting in a detectable fluorescent band and measurement of the effects of dose and sea turtle growth rate on the width of the oxytetracycline band. Such studies would require bone biopsies or fortuitous recovery of postmortem samples. We provide sea turtle oxytetracycline dosing guidelines for use along with bacterial culture and sensitivity results when oxytetracycline is an option for antibiotic treatment, with dose simulations indicating that minimum plasma concentrations of 1 or $2 \mu \mathrm{g} / \mathrm{ml}$ could be achieved with a loading dose of $41 \mathrm{mg} / \mathrm{kg}$ i.m. followed by $21 \mathrm{mg} / \mathrm{kg}$ i.m. q 72 $\mathrm{hr}$ or $82 \mathrm{mg} / \mathrm{kg}$ i.m. followed by $42 \mathrm{mg} / \mathrm{kg}$ i.m. q $72 \mathrm{hr}$, respectively.

Acknowledgments: Funding for this study was provided by the National Oceanic and Atmospheric Administration Fisheries Southeast Fisheries Science Center (40ETNF200095). We thank B. Higgins, T. Fontaine, and R. Zimmerman for facilitating work with the sea turtle collection at the National Marine Fisheries Service Galveston Laboratory; S. Epperly for input on initial planning; R. Trindell and M. Conti for arranging required permits; and D. Plummer for her expertise in performing the high-performance liquid chromatography analysis. This study was conducted under a letter of authorization issued by the Florida Fish and 
Wildlife Conservation Commission. Animal use was reviewed and approved by the North Carolina State University Institutional Animal Care and Use Committee.

\section{LITERATURE CITED}

1. Bjorndal, K. A., A. B. Bolten, R. A. Bennett, E. R. Jacobson, T. J. Wronski, J. J. Valeski, and P. J. Eliazar. 1998. Age and growth in sea turtles: limitations of skeletochronology for demographic studies. Copeia 1998: 23-30.

2. Braun-McNeill, J., S. P. Epperly, D. W. Owens, and R. W. Patterson. 1999. Sex ratios of immature sea turtles: does water temperature make a difference? In: Kalb, H., and T. Wibbels (compilers). Proceedings of the Nineteenth Annual Symposium on Sea Turtle Biology and Conservation. NOAA Technical Memorandum NMFS-SEFSC443. U.S. Department of Commerce. Miami, Florida. Pp. 127-128.

3. Clippinger, T. L., R. A. Bennett, C. M. Johnson, K. A. Vliet, S. L. Deem, J. Oros, E. R. Jacobson, I. M. Schumacher, D. R. Brown, and M. B. Brown. 2000. Morbidity and mortality associated with a new mycoplasma species from captive American alligators (Alligator mississsippiensis). J. Zoo Wildl. Med. 31: 303-314.

4. Coles, W. C., J. A. Musick, and L. A. Williamson. 2001. Skeletochronology validation from an adult loggerhead (Caretta caretta). Copeia 2001: 240-242.

5. Flammer, K., D. P. Aucoin, D. A. Whitt, and D. K. Styles. 1990. Potential use of long-acting injectable oxytetracycline for treatment of chlamydiosis in Goffin's cockatoos. Avian Dis. 34: 228-234.

6. Flammer, K., D. Whitt-Smith, and M. G. Papich. 2001. Plasma concentrations of doxycycline in selected Psittacine birds when administered in water for potential treatment of Chlamydophila psittaci infection. J. Avian Med. Surg. 15: 276-282.

7. Frost, H. M., A. R. Villanueva, H. Roth, and S. Stanisavljevic. 1961. Tetracycline bone labeling. J. New Drugs 1: 206-216.

8. George, R. H. 1997. Health problems and diseases of sea turtles. In: Lutz, P. L., and J. A. Musick (eds.). The Biology of Sea Turtles. CRC Press, Boca Raton, Florida. Pp. 363-385.

9. Gibaldi, M., and D. Perrier. 1982. Pharmacokinetics, 2nd ed. Marcel Dekker, New York, New York.

10. Hansson, L. I. 1967. Daily growth in length of diaphysis measured by oxytetracycline in rabbit normally and after medullary plugging. Acta. Orthop. Scand. Suppl. 101: 1-199.

11. Harms, C. A., G. A. Lewbart, and J. Beasley. 2002. Medical management of mixed nocardial and unidentified fungal osteomyelitis in a Kemp's ridley sea turtle, Lepidochelys kempii. J. Herpetol. Med. Surg. 12: 21-26.

12. Harris, W. H. 1960. A microscopic method of determining rates of bone growth. Nature 188: 1038-1039.

13. Helmick, K. E., D. R. Brown, E. R. Jacobson, and M. B. Brown. 2002. In vitro drug susceptibility pattern of Mycoplasma alligatoris isolated from symptomatic Amer- ican alligators (Alligator mississippiensis). J. Zoo Wildl. Med. 33: 108-111.

14. Helmick, K. E., M. G. Papich, K. A. Vliet, R. A. Bennett, M. R. Brown, and E. R. Jacobson. 2004. Pharmacokinetic disposition of a long-acting oxytetracycline formulation following single-dose intravenous and intramuscular administrations in the American alligator (Alligator mississippiensis). J. Zoo Wildl. Med. 35: 367-384.

15. Higgins, B. M. 2002. Sea turtle husbandry. In: Lutz, P. L., J. A. Musick, and J. Wyneken (eds.). The Biology of Sea Turtles, vol. II. CRC Press, Boca Raton, Florida. Pp. 411-440.

16. Homer, B. L., E. R. Jacobson, J. Schumacher, and G. Scherba. 1994. Chlamydiosis in mariculture-reared green sea turtles (Chelonia mydas). Vet. Pathol. 31: 1-7.

17. Jacobson, E., R. Harman, E. Laille, and L. Maxwell. 2002. Plasma concentrations of praziquantel in loggerhead sea turtles, Caretta caretta, following oral administration of single and multiple doses. Proc. Assoc. Rept. Amphib. Vet. 9: 37-39.

18. Jacobson, E. R. 1999. Use of antimicrobial drugs in reptiles. In: Fowler, M. E., and R. E. Miller (eds.). Zoo and Wild Animal Medicine Current Therapy 4. W. B. Saunders Co., Philadelphia, Pennsylvania. Pp. 190-200.

19. Keller, J. M., J. R. Kucklick, C. A. Harms, and P. McClellan-Green. 2004. Organochlorine contaminants in sea turtles: correlations between whole blood and fat. Environ. Toxicol. Chem. 23: 726-738.

20. Klinger, R. C., and J. A. Musick. 1992. Annular growth layers in juvenile loggerhead turtles (Caretta caretta). Bull. Marine Sci. 51: 224-230.

21. Mallo, K. M., C. A. Harms, G. A. Lewbart, and M. G. Papich. 2002. Pharmacokinetics of fluconazole in loggerhead sea turtles (Caretta caretta) after single intravenous and subcutaneous injections, and multiple subcutaneous injections. J. Zoo Wildl. Med. 33: 29-35.

22. Manire, C. A., H. L. Rhinehart, G. J. Pennick, D. A. Sutton, R. P. Hunter, and M. G. Rinaldi. 2003. Steadystate plasma concentrations of itraconazole after oral administration in Kemp's ridley sea turtles, Lepidochelys kempi. J. Zoo Wildl. Med. 34: 171-178.

23. Mauel, M. J., and D. L. Miller. 2002. Piscirickettsiosis and piscirickettsiosis-like infections in fish: a review. Vet. Microbiol. 22: 279-289.

24. Meijer, L. A., K. G. F. Ceyssens, W. T. deJong, and B. I. deGrève. 1993. Three phase elimination of oxytetracycline in veal calves: the presence of an extended terminal elimination phase. J. Vet. Pharmacol. Ther. 16: 214222.

25. Papich, M. G. 1999. Pharmacokinetics of enrofloxacin in reptiles. Compend. Cont. Educ. Pract. Vet. 21(Suppl. 12M): 110-114.

26. Plumb, D. C. 1999. Veterinary Drug Handbook, 3rd ed. Iowa State Univ. Press, Ames, Iowa. Pp. 475-479.

27. Pye, G. W., D. R. Brown, M. F. Nogueira, K. A. Vliet, R. R. Schoeb, E. R. Jacobson, and R. A. Bennett. 2001. Experimental inoculation of broad-nosed caimans (Caiman latirostris) and Siamese crocodiles (Crocodylus siamensis) with Mycoplasma alligatoris. J. Zoo Wildl. Med. 32: 196-201. 
28. Riviere, J. E., and J. W. Spoo. 2001. Tetracycline antibiotics. In: Adams, H. R. (ed.). Veterinary Pharmacology and Therapeutics, 8th ed. Iowa State Univ. Press, Ames, Iowa. Pp. 828-840.

29. Stamper, M. A., M. G. Papich, G. A. Lewbart, S. B. May, D. D. Plummer, and M. K. Stoskopf. 1999. Pharmacokinetics of ceftazidime in loggerhead sea turtles (Caretta caretta) after single intravenous and intramuscular injections. J. Zoo Wildl. Med. 30: 32-35.

30. Stamper, M. A., M. G. Papich, G. A. Lewbart, S. B. May, D. D. Plummer, and M. K. Stoskopf. 2003. Pharmacokinetics of florfenicol in loggerhead sea turtles (Caretta caretta) after single intravenous and intramuscular injections. J. Zoo Wildl. Med. 34: 3-8.
31. Walsh, P. (ed). 2001. Physician's Desk Reference. Medical Economics Data Production, Montvale, New Jersey.

32. Whittem, T. L., A. L. Johnson, C. W. Smith, D. J. Schaeffer, B. R. Coolman, S. M. Averill, T. K. Cooper, and G. R. Merkin. 1999. Effect of perioperative prophylactic antimicrobial treatment in dogs undergoing elective orthopedic surgery. J. Am. Vet. Med. Assoc. 215: 212216.

33. Yamaoka, K., T. Nakagawa, and T. Uno. 1978. Application of Akaike's information criterion (AIC) in the evaluation of linear pharmacokinetic equations. J. Pharmacokinet. Biopharm. 6: 165-175.

Received for publication 8 September 2003 